\title{
Bone rarefaction and crush fractures in juvenile chronic arthritis
}

\author{
U ELSASSER, B WILKINS, R HESP, D I THURNHAM, J REEVE, AND B M ANSELL \\ Clinical Research Centre, Northwick Park Hospital, Harrow, Canadian Red Cross Memorial Hospital, \\ Taplow, Berks, and Department of Human Nutrition, London School of Hygiene and Tropical Medicine
}

SUMMARY Seventy children with juvenile chronic arthritis have had measurements of cortical and trabecular bone density in one or both radii. In 7 children with unilateral disease of one wrist, there was a substantial reduction in growth on the affected side. Trabecular bone density in the distal radius was reduced in the main group of 63 patien ts compared with controls, and this deficit wes appreciably worse if the wrist was clinically affected by disease or if the child was being treated with steroids. Cortical bone density in the midshaft was less affected. Crush fractures of the spine were associated with more prolonged periods of bed rest, steroid therapy, radial trabecular bone density more than 2 standard deviations below normal, and subnormal 25-hydroxycholecalciferol concentrations in the serum. Since steroid therapy is often mandatory the main therapeutic implications are that the more severely affected child often needs vitamin D supplementation in 'physiological' dosage, and that early mobilisation and reduction of steroid dosage should be constant aims.

In the management of juvenile chronic arthritis, particularly the systemic form, and occasionally in severe arthritis, it is still necessary to treat with oral corticosteroids. Although every effort is made to minimise side effects by the use of an alternate-day regimen, a few patients will need daily steroids. Rarefaction of trabecular bone in the spine leading to crush fractures may result.

The purpose of this study was to determine which clinical, radiological, and biochemical measurements have discriminatory value for existing or predictive value for crush fractures of the spine. Our patients also had atraumatic measurements of trabecular and cortical bone density in the wrist, using computed tomography, and plasma 25-hydroxyvitamin D concentrations were measured in just over half of them.

\section{Materials and methods}

Patients came either from the juvenile outpatients' service at Northwick Park Hospital, or from the special unit for juvenile rheumatism at the Canadian Red Cross Memorial Hospital, Taplow where children with serious problems requiring long-term rehabilitation are admitted. Sixty-three patients were studied during a 9-month period. In addition to the 30 patients treated with glucocorticoids, 6 had received adrenocorticotrophic hormone, and the remaining 27 had at no time been exposed to either form of treatment. At the time of the bone density measurements the following clinical details were recorded: age, height and weight, duration of illness, previous systemic illness, present systemic illness, the degree of joint involvement, functional state (graded 1 to 4 ), the total steroid dosage expressed as milligrams of prednisone or equivalent, cumulated over the entire duration of treatment, together with the treatment regimen (that is daily, alternate day, or both), the cumulative duration of pre-existing periods of bed rest exceeding 6 weeks, the number of crush fractures, and the presence or absence of clinical joint involvement in the measured wrist.

Generally it was possible to measure the following biochemical indices: albumin, calcium, phosphate, alkaline phosphatase, together with the haemoglobin concentration. In addition, 25-hydroxycholecalciferol $(25(\mathrm{OH}) \mathrm{D})$ was, if possible, measured in the same samples by a modification of the method of Haddad and Chyu. ${ }^{1}$ 25(OH)D was separated from serum as described $^{1}$ but eluted off the column by $25 \mathrm{ml}$ absolute ether. The binding protein used was rachitic rat serum at a dilution of $1: 10000$ in barbital buffer, pH 8.6 containing $0.1 \%$ bovine serum albumin. Binding took place at $4^{\circ} \mathrm{C}$ for 2 hours. Alkaline phosphatase measurements were made by the method of Kind and $\mathrm{King}^{2}$ and expressed as a percentage of the upper limit of normal for the child's age. ${ }^{3}$ 
Trabecular bone density (TBD) in the radius was measured with an 'Isotom' purpose-built CT densitometer which uses a ${ }^{125}$ I source. TBD $($ per $\mathrm{cm})$ is the mean attenuation coefficient for the central half of the bone cross-section containing trabecular bone. ${ }^{4}$ The site chosen on the radius was between 8 and $10 \%$ of the distance between the styloid and ulnar processes measured from the styloid process.

The site chosen for measuring the cortical bone density (BD, per $\mathrm{cm}$ ) was the junction of the distal one-third and proximal two-thirds of the radius. The radiation dose received by each patient was calculated to be 2 mrem at the measurement site and considerably less than 0.1 mrem to the whole body, much lower than is possible with conventional $x$-ray equipment, and equivalent to about 8 hours' natural background radiation at sea level. The procedure was approved both for patients and controls by the hospital ethical committee.

To find out if loss of bone mass was owing to local joint involvement or systemic factors, an additional 7 children with unilateral wrist involvement had densitometry performed on both forearms.

The control subjects were children of members of staff or siblings of the patients. They were compared as a group with another population of normal children who had previously been studied in Zurich. If appropriate statistical tests confirmed the homogeneity of the two populations, they were combined for the purpose of calculating normal values.

Table 1 Normal values for trabecular and cortical bone density in children aged $5-15$ years, in 49 children in Zurich (Switzerland), and 28 in Harrow (UK)*

\begin{tabular}{llll}
\hline & Zurich & Harrow & Differences \\
\hline $\begin{array}{c}\text { Trabecular bone } \\
\text { density (per cm) } \\
\text { Mean }\end{array}$ & 0.730 & 0.683 & 0.047 \\
$\begin{array}{c}\text { SD } \\
\text { Cortical bone } \\
\text { density (per cm) } \\
\text { Mean }\end{array}$ & 0.086 & 0.086 & $t=2.35, \mathrm{P}<0.05$ \\
SD & 1.966 & 2.232 & 0.266 \\
\hline
\end{tabular}

*Boys and girls were combined.

\section{Results}

Normal values for trabecular and cortical bone density (Table 1). TBD did not differ significantly between the sexes, nor was there a significant trend with age. However, the Zurich mean value for girls was significantly higher than the British mean value, so only the latter data were used for reference. Conversely, the British mean value for cortical bone density was higher than the Swiss in both girls and boys. Unlike these two parameters, cross-sectional area of the radial midshaft was dependent on age, so the normal range for age was obtained from the linear regression of cross-sectional area on age, which from the combined data was given by the equation:

CA (cross-sectional area $)=0.049 \times($ age, years $)+$ $0 \cdot 229 \pm 0 \cdot 116, t=6 \cdot 8, \mathrm{P}<0 \cdot 001$

Spinal crush fractures (Table 2). At entry, 9 patients each had at least one spinal crush fracture; during the ensuing 18 months 4 had further crush fractures. Five other patients with previously intact spines fractured during the same period.

The clearest association with the crush fractures was steroid therapy. To normalise the distributions of total steroid doses, square roots were taken in each case before the two groups were compared statistically. The crush fracture group had, on average, received 9.1 times as much treatment with steroids as the non-fracture group (Student's $t=5 \cdot 1, \mathrm{P}<0 \cdot 001$ ). There was also an association between the crush fracture syndrome and duration of bed rest, the crush fracture group having endured a mean of 9.7 months compared with 2.1 months for the non-crush fracture group $(\mathrm{P}<0.01$, Wilcoxon's rank sum test). There were no significant associations between crush fractures on the one hand and height, weight, disease duration, haemoglobin, or any of the biochemical indices other than $25(\mathrm{OH}) \mathrm{D}$, on the other.

Associates of steroid therapy. As expected, the total steroid dose (expressed as its square root, $\sqrt{ } \mathrm{s}$ units)

Table 2 Clinical and biochemical indices in children with juvenile chronic arthritis

\begin{tabular}{|c|c|c|c|c|c|c|c|c|c|}
\hline & \multirow{2}{*}{$\begin{array}{l}\text { Duration of } \\
\text { disease (years) }\end{array}$} & \multicolumn{2}{|l|}{ Centiles } & \multirow{2}{*}{$\begin{array}{l}\text { Months of } \\
\text { bed rest }\end{array}$} & \multirow{2}{*}{$\begin{array}{l}\text { Albumin } \\
(g / l)\end{array}$} & \multirow[t]{2}{*}{$H b(g / d l)$} & \multirow{2}{*}{$\begin{array}{l}\text { Alkaline } \\
\text { phosphatase } \\
\% \text { upper limit } \\
\text { of normal }\end{array}$} & \multirow{2}{*}{$\begin{array}{l}\text { Calcium } \\
(\mathrm{mmol} / \mathrm{l})\end{array}$} & \multirow{2}{*}{$\begin{array}{l}\text { Phosphate } \\
\text { (mmol/l) }\end{array}$} \\
\hline & & Height & Weight & & & & & & \\
\hline \multicolumn{10}{|c|}{$\begin{array}{l}\text { Crush fractures } \\
(7<n \geqslant 8)\end{array}$} \\
\hline Mean & $7 \cdot 9$ & 6 & 11 & $9 \cdot 9$ & $35 \cdot 0$ & $10 \cdot 1$ & 64 & $2 \cdot 33$ & $1 \cdot 38$ \\
\hline SD & $3 \cdot 7$ & 17 & 28 & $7 \cdot 4$ & $3 \cdot 4$ & $1 \cdot 6$ & 41 & 0.13 & 0.29 \\
\hline \multicolumn{10}{|c|}{$\begin{array}{l}\text { No crush fracture } \\
(37<n<53)\end{array}$} \\
\hline Mean & $4 \cdot 1$ & 30 & 28 & $2 \cdot 1$ & $38 \cdot 7$ & $10 \cdot 7$ & 54 & $2 \cdot 31$ & $1 \cdot 37$ \\
\hline SD & $3 \cdot 3$ & 30 & 32 & $4 \cdot 7$ & $4 \cdot 3$ & $1 \cdot 6$ & 19 & $0 \cdot 12$ & 0.22 \\
\hline
\end{tabular}


was associated with a downwards trend in the height centile $(-0.26$ centiles per $\sqrt{ }$ s unit, $t=2 \cdot 90)$, reduced serum albumin $(-0.04 \mathrm{~g} /$ litre per $\sqrt{ } \mathrm{s}$ unit, $t=2.44)$, and the previously observed ${ }^{5}$ biphasic response in the weight centile. Those who had received steroids for a short time were fairly heavy while those who had received prolonged therapy were substantially lighter than the non-steroid treated group.

There were substantial deficits in TBD in both the steroid and non-steroid groups compared with controls, amounting to $-2 \cdot 2$ and -1.3 standard deviations (SDs) respectively $(P<0 \cdot 01)$. The reduction of $0.2 \mathrm{SDs}$ in cortical bone density in the non-steroid group was not significant; however, in the steroid group cortical bone density was also reduced $(-1.0$ SDs, $t=3 \cdot 1, P<0.05$ ), but only to the level seen in normal children in Zurich. The correlation between bone density and TBD in this group was weak $(\mathrm{r}=0.50, \mathrm{P}<0.05)$.

Wrist involvement and bone density. In the main group of patients, local inflammatory disease was associated with more severe deficits in bone mineral in the ipsilateral forearm (Table 3). Additionally, the cross-sectional area of the radius mid-shaft was reduced by $38 \%$ compared with normal $(t=3 \cdot 83)$ if the wrist was affected.

In the 7 patients with unilateral joint involvement, none of whom was on steroid therapy, the difference between TBD in the two wrists was not significant (Table 4). However, there were substantial and

Table 3 Influence of local disease*

\begin{tabular}{lll}
\hline Trabecular bone density & No steroids & Steroid therapy \\
\hline Deficit, unaffected wrist & $-0.9, t=2.50$ & $-1 \cdot 1, t=2.75$ \\
Deficit, affected wrist & $\mathrm{n}=12, \mathrm{P}<0.02$ & $\mathrm{n}=9, \mathrm{P}<0.02$ \\
Student's $t$ difference & $\mathrm{n}=1.8, \mathrm{P}=4.05$ & $-2.8, t=7.11$ \\
$\quad$ Affected versus unaffected & $1.62 \mathrm{NS}$ & $\mathrm{n}=15, \mathrm{P}<0.001$ \\
\hline
\end{tabular}

*Results expressed in numbers of standard deviations from normal.

Table 4 Comparison of bone density indices in affected compared with unaffected wrists

\begin{tabular}{llll}
\hline Case & \multicolumn{2}{l}{ Ratio affected: unaffected wrist } \\
\cline { 2 - 4 } & $\begin{array}{l}\text { Trabecular } \\
\text { bone density }\end{array}$ & $\begin{array}{l}\text { Cortical bone } \\
\text { density }\end{array}$ & $\begin{array}{l}\text { Cross-sectioned } \\
\text { area }\end{array}$ \\
\hline 63 & 1.06 & 1.00 & 0.84 \\
64 & 0.92 & 0.99 & 0.98 \\
65 & 0.68 & 1.02 & 0.68 \\
67 & 0.85 & 1.10 & 0.79 \\
68 & 0.92 & 0.88 & 1.02 \\
69 & 1.00 & 1.06 & 0.71 \\
70 & 0.90 & 1.03 & 0.78 \\
Mean & 0.90 & 1.01 & 0.83 \\
SD & 0.12 & 0.07 & 0.13 \\
P* & NS & NS & $<0.02$ \\
\hline
\end{tabular}

*Different from 1.0. significant differences between the cross-sectional areas of the radial mid-shafts, suggesting that retardation of bone growth on the affected side was an associate of local disease.

25(OH) cholecalciferol concentrations. Of those measured only $9(31 \%)$ of the 29 inpatients at the unit for juvenile rheumatism had an acceptable vitamin D nutritional status $(25(\mathrm{OH}) \mathrm{D}$ concentrations $>10 \mathrm{ng} / \mathrm{ml}$ ). Five of the 9 results at Northwick Park were satisfactory by this criterion. Nine patients with crush fracture had a mean $25(\mathrm{OH}) \mathrm{D}$ concentration of $4.6 \mathrm{ng} / \mathrm{ml}$, which was significantly $(P<0.01)$ lower than the mean of $9.8 \mathrm{ng} / \mathrm{ml}$ observed in the remainder (both distributions normalised on a log scale). There was a poor, but just significant correlation between TBD and 25(OH)D concentrations $(r=0.37, P<0.05)$.

Abnormal trabecular bone density. Twenty-two patients had TBD values more than 2 SDs below normal and, of these, 7 had crush fractures already, and 4 developed them subsequently $\left(\chi^{2}=12.7\right.$ with Yates's correction; $P<0 \cdot 01$ ). One child was studied within 3 months of the start of the disease and had a normal TBD value; after a stormy course including treatment with high-dose steroids she subsequently developed crush fractures, but in her case TBD fell only by a trivial amount from a fairly normal value of 0.67 to 0.65 over 18 months. Another patient who had had crush fractures 15 years previously had a normal TBD value, and his disease was quiescent.

\section{Discussion}

Control data. We could find no explanation for the small but significant differences in mean bone density indices between the British and Swiss children (Table 1). It seems possible that these indices vary between different populations or social classes. There are two implications. Firstly, small mean differences between index and control groups (as in cortical bone density in our steroid-treated group) do not necessarily imply structural weakness despite being statistically significant; and secondly there may be advantages in accuracy if local controls are recruited rather than reliance being placed on data obtained elsewhere, at least in studies on children.

Loss of bone. Badley and Ansell ${ }^{6}$ have shown that steroid therapy leads to loss of trabecular bone and crush fractures. Clearly in these patients there may be additional factors, notably vitamin $\mathbf{D}$ depletion. This is almost certainly due to the abnormally house- and hospital-bound existence and poor appetite of the more severely affected children leading to lack of exposure to sunlight with no 
dietary compensation. As Gupta et al. ${ }^{7}$ have pointed out, when $25(\mathrm{OH}) \mathrm{D}$ concentrations fall below $5 \mathrm{ng} / \mathrm{ml}$ the ability of the normal kidney to synthesise the active hormonal form, $1,25(\mathrm{OH})_{2} \mathrm{D}$, is compromised and overt osteomalacia or rickets is likely to supervene. However, in adult patients on steroid therapy osteoblast function is depressed ${ }^{8}$ and the production of exuberant osteoid in response to vitamin D deficiency may be impaired. Instead, a modified syndrome of accelerated osteoporosis is a possible sequel.

Local and systemic effects of disease. The study in the children with unilaterally affected wrists suggests that local disease affects mainly bone growth (as measured by cross-sectional area) rather than bone density (mass per unit volume). On the other hand, TBD was significantly lower than normal in children not on treatment with steroids, particularly those in whom the wrists were affected who, overall, must have had more severe disease than those with clinically normal wrists. Steroid therapy was associated with even greater deficits. We conclude that in juvenile chronic arthritis there is a significant deficit of trabecular but not of cortical bone, probably associated with a systemic factor. This is made worse by steroid therapy. Local disease additionally inhibits bone growth, as can unilateral disorders-such as poliomyelitis, hemiphegia, and even unilateral postencephalitic parkinsonism. ${ }^{9}$ This may be secondary to disuse. In view of the low vitamin D status of many of these children it is impossible to say whether the systemic factor is directly related to the disease.

Implications for management. We conclude that some crush fractures can be avoided, provided there is adequate vitamin $\mathbf{D}$ nutrition and optimal modulation of steroid therapy using the lowest adequate dose, and if possible alternate-day therapy. It is essential to appreciate that in children the skeleton turns over much more rapidly than in adults and that spinal osteoporosis can, given adverse circumstances, develop to the point of fracture within a fairly short space of time. Prolonged periods of bed rest will aggravate such a tendency, and for this there is support from our data. Children with TBD values more than 2 SDs below normal appeared at particular risk. Since steroid therapy is mandatory in some of these children, the further role of bone densitometry is to enhance the assessment of future therapeutic developments. Meanwhile, we are taking steps to ensure that all our patients with juvenile chronic arthritis have vitamin $D$ status guaranteed by adequate exposure to sunlight or by dietary supplements of the vitamin. In this group calcium and vitamin $D$ tablets are unsuitable because they require chewing, and diluted calciferol solution or one of the proprietary multi-vitamin preparations in a dose of 400-2000 IU daily is preferable. $^{10}$

We thank Ms J A Dattani, Dr D Macauley, and Dr D Thomas for their enthusiastic collaboration in this study.

\section{References}

1 Haddad J G, Chyu K J. Competitive protein binding radioassay for 25-hydroxycholecalciferol.J Clin Endocrinol Metab 1971; 33: 992-5.

2 Kind P R N, King E J. Estimation of plasma phosphatase by determination of hydrolised phenol with amino anti-pyrine. J Clin Pathol 1954; 7 : 322-6.

3 Round J M. Plasma calcium, magnesium, phosphorus, and alkaline phosphatase levels in normal British schoolchildren. Br Med J 1973; iii: 137-40.

4 Elsasser U, Reeve J. Bone density measurement with computed tomography. Br Med Bull 1980; 36: 293-6.

5 Ansell B M, Bywaters E G L, Growth in Still's disease. Ann Rheum Dis 1956; 15: 295-319.

6 Badley B W D, Ansell B M. Fractures in Still's disease. Ann Rheum Dis 1960;19: 135-42.

7 Gupta M M, Round J M, Stamp T C B. Spontaneous cure of vitamin-D deficiency in Asians during summer in Britain. Lancet 1974; i: 586-8.

8 Bressot C, Meunier P J, Chapuy M C, Lejeune E, Edouard C, Darby A J. Histomorphometric profile, pathophysiology, and reversibility of corticosteroidinduced osteoporosis. Metabolic Bone Disease and Related Research 1979; 1: 303-11.

9 Gaunt R T. Retarded growth of limbs as a sequel of encephalitis lethargica. Lancet 1949 ; $i$ : 1049-51.

10 Heath D A. Vitamin D therapy. Prescribers $J 1981 ; 21$ : 164-71.

Correspondence to Dr J Reeve, Clinical Research Centre, Watford Road, Harrow, Middlesex HA1 3UJ.

Received 17 November 1981 